\title{
Management Strategies in Multi-year Enterprise Risk Management
}

\author{
Dorothea Diers \\ Risk Management, Provinzial NordWest Holding and University of Ulm, Provinzial Allee 1, Muenster \\ 48131, Germany.
}

In enterprise risk management, strategies should be evaluated and managed from a multiyear view. In this paper, we present a multi-year model approach and apply a multi-year riskcapital concept to enable the company's "Own Risk and Solvency Assessment" as a part of enterprise risk management on a multi-year basis. We show under which assumptions an allocation method gives the "right" strategic incentives. We illustrate the usefulness of the concept for managerial decision support using data from a German non-life insurer.

The Geneva Papers (2011) 36, 107-125. doi:10.1057/gpp.2010.39

Keywords: non-life insurance; Solvency II; multi-year internal risk models; capital allocation

\section{Introduction}

Major changes in competitive behaviour, recent dynamics in capital markets and fundamental changes in regulatory requirements (e.g. Solvency II for European Union member countries) have placed increasing challenges on the management of insurance the companies. Management is faced with a complex decision-making and strategic task of allocating and managing capital resources efficiently. This requires a suitable insurance portfolio structure in combination with an adequate asset allocation towards the insurance cash flows. In this context the appropriate use of diversification effects plays an important role. As a result most companies are currently developing modern management techniques such as enterprise risk management (ERM; see Liebenberg and Hoyt). ${ }^{1}$

Internal risk models (see Kaufmann et al.) $)^{2}$ provide an important instrument in supporting managerial decision-making in a risk-return-oriented strategy. Discussions at European level in the context of Solvency II have also emphasised the importance of internal risk models in supporting management decision-making processes. These models should also be used in a company's "Own Risk and Solvency Assessment" (ORSA; see CEIOPS). ${ }^{3}$

While in the Solvency II framework the time horizon is one year, the strategic risk-return profile of the insurer should be set according to multi-year calculations. In the actual literature several questions concerning the use of internal models in a multi-year management context are not answered to date. Therefore in this paper we present a multi-year

\footnotetext{
${ }^{1}$ Liebenberg and Hoyt (2003).

${ }^{2}$ Kaufmann et al. (2001).

${ }^{3}$ CEIOPS (2008).
} 
model approach, which allows applying a multi-year risk-capital concept to enable the company's strategic management on a multi-year basis. This helps management to answer the essential question: "How much risk capital the company will need to be able to survive the next five years - taking five future underwriting years into account — without a need for external capital?" (section "Model approach for measuring multi-year risk capital").

In the context of ERM a capital allocation method is needed in order (1) to set risk limitations for different segments, for example different lines of business, and (2) to quantify the effect of management strategies on risk-adjusted performance indicators, defined per segment. Generally there is no known allocation method giving "right" incentives for each portfolio structure and each managerial problem. We give examples for capital allocation giving "wrong" incentives for the company in order to point out the importance of choosing adequate allocation methods for the different managerial problems. Then we show under which assumptions increasing the economic value added $(E V A)$ on segment-level leads to an increase of the $E V A$ for the company, so that the underlying allocation method gives the "right" strategic incentives for the segment (section "Capital allocation for performance management in ERM"). We analyse the practical application in a simulation study based on real-world data.

In value and risk-based management, strategies should be selected in such a way as to fulfil the requirements on risk-capital coverage with economic capital (e.g. risk limitation) while achieving the highest possible return. One goal is to ensure effective risk diversification, which is hardly possible without the help of internal models. Therefore, for example, management has to decide which strategy might improve the risk and return situation of a company if not enough risk capital is availablechanging the asset allocation by lowering the part of high-risk investments, lowering risk via introduction of deductibles for the policy-holders in storm insurance policies, extending reinsurance cover, or any suitable combination of these or further strategies.

We use real-world data and an internal model actually in use at a medium-sized German non-life insurance company to examine the effectiveness of different management strategies on a non-life insurer's performance indicators such as EVA and return on risk-adjusted capital (RoRAC; section "Simulation study: Management strategies in the context of multi-year ERM"). We give a concrete example of how management could define requirements on risk and performance in a multi-year framework. We show how strategic decision processes can be implemented using the results from multi-year internal models in order to fulfil management requirements. With the simulation study we want to encourage the use of multi-year internal models in strategic ERM and in the ORSA process, which will be required in the new regulatory framework of Solvency II.

The aim of this paper is not only grounded in academic research, but also of high importance for insurance practice. The study wants to give a realistic and helpful idea of multi-year ERM processes for strategic management of different business segments, such as different lines of business, reinsurance, investments, where capital allocation plays an important role. Moreover the simulation study should give an idea of the ORSA process. In addition to practitioners, regulators will also benefit from this paper's results. Since the "use test" will play an important role for the approval of internal models, regulators will check if the internal model is used as a base for management decisions in ERM and in the ORSA process, whereby both should be based on a time horizon of several years. 


\section{Model approach for measuring multi-year risk capital}

We have based this model design of an internal simulation model in non-life insurance by modelling strategically important insurance segments and asset classes according to economic principles, and simulating the results with reference to the underlying dependencies. We rely on the Dynamic financial analysis (DFA) framework for a simplified non-life insurance company. ${ }^{4}$ An economic result, EcRes ${ }_{t}$, projection for a future calendar year, $t$, may be written by the change of corporate economic capital, EcCap, within the calendar year considered: ${ }^{5}$

$$
\begin{aligned}
E_{c} \operatorname{Res}_{t} & =E_{c} \operatorname{Cap}_{t}-E_{c} \operatorname{Cap}_{t-1} \\
& =E_{c} \operatorname{Res} \operatorname{Liab}_{t}+\operatorname{EcRes}_{\mathrm{A}} \mathrm{s}_{t}-O_{t}-A_{t},
\end{aligned}
$$

where: $E c \operatorname{ResLiab}_{t}=$ net insurance result at time $t$ (insurance result after reinsurance), EcResAs ${ }_{t}=$ investment result at time $t, O_{t}=$ result from operational risk at time $t$, $A_{t}=$ tax at time $t$.

For simulating insurance results three types of claims - catastrophe, large and attritional (base) claims - are modelled, which can be simulated according to adequate probability distributions, subject to a given dependency structure. Therefore, for example, we use a Gumbel copula for modelling the tail-dependence structure at the level of simulated returns of the two lines of business storm and hail. For modelling reinsurance contracts in internal models, see Diers ${ }^{6}$ and Eling and Toplek. $^{7}$

The selected risk measure, $\rho$, for calculating risk capital may be applied to the random variable EcRes in $_{t}$ order to determine the one-year risk-capital requirement $\rho\left(E c \operatorname{Res}_{1}\right)$.

Usually, management will require that extreme risks such as natural catastrophe claims and large claims be viewed from a perspective spanning several years, so that the following question can be answered: How much risk capital does a company currently provide to maintain a certain confidence level to ensure its status as a going concern for another five years, that is taking five future underwriting years into account, without needing external capital sources?

To address issues of this nature, we defined a "multi-year" risk-capital concept taking $n, n \in I N$, future years into account and referring to the random MaxLoss variable defined as follows:

$$
\operatorname{MaxLoss}(n)=\underset{1 \leqslant t \leqslant n}{\operatorname{MAIMUM}\left\{\text { CumLoss }_{t}\right\}},
$$

where

$$
\text { CumLoss }_{1}=- \text { EcRes }_{1}
$$

and

\footnotetext{
${ }^{4}$ As considered by Eling and Toplek (2009a).

${ }^{5}$ Economic capital is defined as the difference between the market value of assets and liabilities (best estimate plus market value margin). We have taken a somewhat simplified view, ignoring for example other assets and liabilities. We refer to net earnings before dividend payout.

${ }^{6}$ Diers (2007).

${ }^{7}$ Eling and Toplek (2009b).
} 


$$
\text { CumLoss }_{t}=\text { CumLoss }_{t-1}-\text { EcRes }_{t}, \quad 1 \leqslant t \leqslant n .
$$

MaxLoss represents the maximum of the amount that needs to be covered over the years for each simulation. This amount needs to be provided at time $t=0$ in the simulation path to allow the insurance company to cover all losses incurred over the entire period simulated ( $n$ years) without external capital supply in this simulation path.

The selected risk measure, $\rho$, can now be applied to the MaxLoss: $\Omega \rightarrow \mid \mathrm{R}$ in order to determine the risk-capital requirement, for example tail value at risk $(T V a R)$, which is a coherent risk measure for random variables with continuous distribution:

$$
\rho(\operatorname{Max} \operatorname{Loss}(n))=T \operatorname{VaR}_{\alpha_{n}}(\operatorname{Max} \operatorname{Loss}(n)) .
$$

TVaR of a random variable of loss $L$ is defined as

$$
\begin{aligned}
& \operatorname{TVaR}_{\alpha}(L)=E\left[L \mid \operatorname{LVaR}_{\alpha}(L)\right] \\
& \quad \text { at confidence level } 1-\alpha, \alpha \in(0,1),
\end{aligned}
$$

with value at risk $\operatorname{VaR} .^{8}$ The confidence level $1-\alpha_{n}$ may decrease with increasing values of $n$. By definition, the multi-year risk capital is always at least as high as the one-year risk capital for values of $\alpha_{n}=\alpha_{1}=\alpha$. If the insurance company can cover its multi-year risk capital with its own economic capital at $t=0, E c C a p_{0}$, the following will apply:

$$
\operatorname{EcCap}_{0} \geqslant \rho(\operatorname{Max} \operatorname{Loss}(n))
$$

The company can therefore cover all losses that may be incurred over the simulation period without external capital supply at a probability of more than $1-\alpha_{n}{ }^{9}$

The multi-year risk capital concept can be suitable as a strict constraint for internal risk models aimed at addressing strategic issues in an ORSA (see Elderfield), ${ }^{10}$ which is required in the Solvency II context (see CEIOPS ${ }^{3}$ ). It should be noted, however, that we take a pure solvency perspective here and that the risk-based capital is a lower bound, not necessarily the optimal capital level. The optimum equity level with optimum company division strategy should be determined by shareholder value (see Gründl and Schmeiser). ${ }^{11}$

Figure 1 shows the structure of an internal DFA risk model (see Diers). ${ }^{6}$

\footnotetext{
${ }^{8}$ The $V a R$ of a loss random variable $L$ is defined as $\operatorname{VaR}(L)=Q_{1-a}(L)=\inf \left[x \in R: F_{L}(x) \geqslant 1-\alpha\right]$. See Artzner et al. (1999) for the properties of these risk measures (VaR, TVaR), including advantages and disadvantages.

${ }^{9}$ The idea of calculating risk-based capital in a multi-year context was already presented in German language in a conference proceeding (Diers, 2008b). For a discussion of the properties of multi-year risk capital and a literature review see Diers (2010), where we concentrate on developing the properties of the new risk capital concept and illustrate the concept in an application to real world data.

${ }^{10}$ Elderfield (2009).

${ }^{11}$ Gründl and Schmeiser (2002).
} 


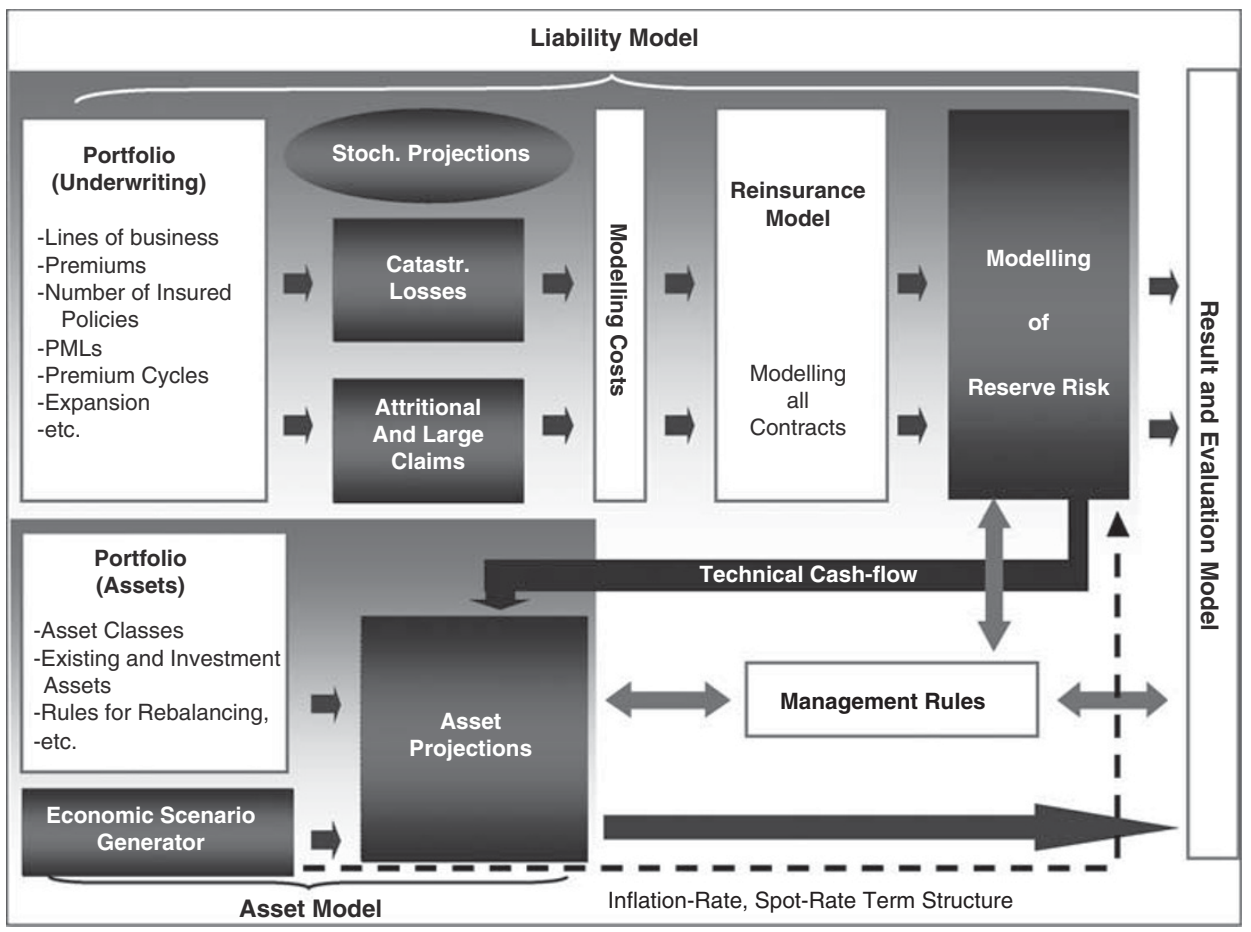

Figure 1. Structure of an internal DFA risk model.

\section{Capital allocation for performance management in ERM}

The aim of risk-adjusted performance strategy is to optimise the risk-return situation of the company with restrictions such as compliance with risk-capital requirement, accounting regulations and supervisory regulations. The wide variety of restrictions such as taking into account cross-selling and cross-cancellation effects, the effects of price-sales functions, etc. make a highly complex task of solving this optimisation problem. We therefore refer to improvement in risk-return trade-off rather than optimisation in the whole company, where we chose out of a variety of potential strategies the best strategy with the most positive effect on the risk-adjusted key performance indicators presented in the following.

We refer to the one-year RoRAC

$$
\begin{aligned}
\text { RoRAC } & =\frac{\text { ExpectedResult }}{\text { RiskCapital }} \\
& =\frac{E\left(\text { EcRes }_{1}\right)}{\rho\left(- \text { EcRes }_{1}\right)},
\end{aligned}
$$

and risk-adjusted economic value-added

$$
\begin{aligned}
E V A & =E V A \_r a \\
& =E(E c \operatorname{Res} 1)-r_{C a p} \cdot \rho\left(-E c \operatorname{Res}_{1}\right)
\end{aligned}
$$


112

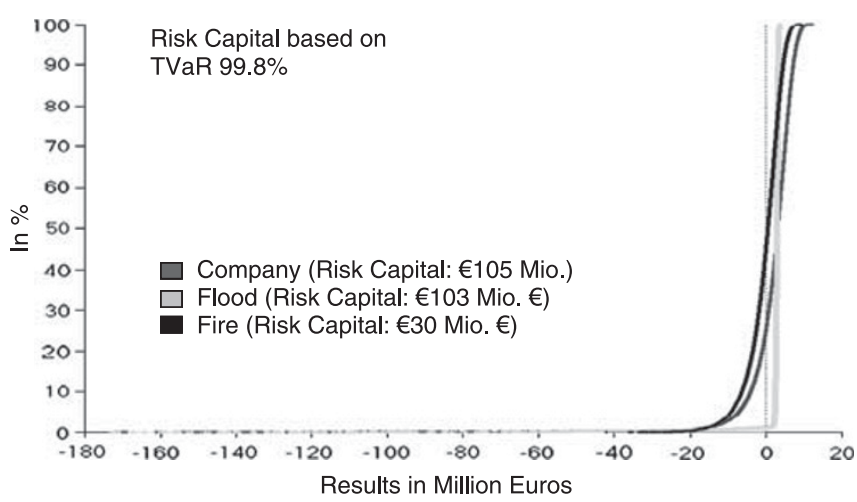

Figure 2. Simulated distribution functions of results (100,000 simulations).

as risk-adjusted performance indicators. In the following, we set the capital costs $r_{c a p}=0.15$, referring these to risk capital. This yields risk-adjusted $E V A_{-} r a$.

Since strategic management has to be applied at segment level, profitable strategies for the company should be identified by appropriate allocation of risk capital and the resulting performance indicators at segment level. Therefore an adequate capital allocation is needed, leading to the "right" incentives.

We want to start this section demonstrating the problems of capital allocation in practice, using an example derived from real data of a German non-life insurance company, which were transformed so as to change the absolute values but not the underlying risk structure.

We consider a company with two lines of business flood with loss $L_{1}$ and fire with loss $L_{2}$ and the company losses $L$. The underlying claims of flood and fire are assumed to be stochastically independent (Figure 2). ${ }^{12}$

The distribution of flood results shows a high skewness. Flood results are dominated by extremely high losses occurring with a very low probability $(<1$ per cent) while the positive results (probability $\geqslant 99$ per cent) are characterised by a very low volatility. The extremely high losses lead to the standard deviation $\sigma\left(L_{1}\right)=5.02 \cdot 10^{6}$. In contrast to flood, negative as well as positive fire results are very volatile. The maximum simulated loss in fire is $€ 42$ million, in flood it is $€ 172$ million. The high volatility of fire results lead to the standard deviation $\sigma\left(L_{2}\right)=4.64 \cdot 10{ }^{6}$

We use two allocation principles often used in practice for capital allocation, the covariance principle and the $T V a R$ principle.

For business segments $i(1 \leqslant i \leqslant n)$ with loss $L_{i}$ and the company losses $L$ the allocation based on the covariance principle is defined by the allocation factors: ${ }^{13}$

$$
x_{i}=\frac{\operatorname{Cov}\left(L_{i}, L\right)}{\operatorname{Var}(L)}, \quad 1 \leqslant i \leqslant n .
$$

\footnotetext{
${ }^{12}$ See also Diers (2008a).

${ }^{13}$ See Denault (2001).
} 
The TVaR principle originates from risk theory, and is based on linearity of expectation values. According to the $T V a R$ principle, the risk capital required for business segments $i(1 \leqslant i \leqslant n)$ with loss $L_{i}$ using the TVaR as risk measure is as follows:

$$
\rho_{\text {TVaR }}\left(L_{i} \mid L\right)=E\left[L_{i} \mid \operatorname{LVaR}_{\alpha}(L)\right]
$$

$T V a R$ allocation is a coherent allocation principle suitable for identifying high-risk factors that dominate the risk situation of the company, as it allocates the amount of risk capital to each segment as contributes to the whole risk capital. ${ }^{14} \mathrm{We}$ have defined this allocation method using $T V a R$ as risk measure. (There is a more generalised definition without coherence in the allocation method). ${ }^{15}$

Now we calculate the amount of allocated risk capital for fire and flood based on covariance principle with underlying risk measure TVaR 99.8 per cent. Because fire and flood results are assumed to be stochastically independent, covariance principle

$$
\begin{aligned}
& \frac{\operatorname{Cov}\left(L_{2}, L\right)}{\operatorname{Var}(L)}=\frac{\sigma^{2}\left(L_{2}\right)}{\sigma^{2}\left(L_{1}\right)+\sigma^{2}\left(L_{2}\right)} \\
& =\frac{21.53}{46.7}=0.46 .
\end{aligned}
$$

leads the allocated risk capital $0.46 \cdot € 105$ million $=€ 48.3$ million for fire (see Figure 2 ). This allocated risk capital is much higher than its stand-alone risk capital of $€ 30$ million. ${ }^{16}$ Moreover it exceeds the maximum simulated loss of $€ 42$ million. Such effects lead to "wrong" incentives for the segment. In this case leaving the company would be an advantage for the fire segment.

In contrast to the covariance principle the $T V a R$ principle takes into account the contribution of risk amount of each segment to the risk capital of the company (Figure 3).

Generally there is no known allocation method (including coherent allocation methods) giving "right" incentives for each portfolio structure and each managerial problem. ${ }^{17}$ In the following, we will be using the $T V a R$ principle for capital allocation. However, this method can give "wrong" management incentives, as the following example will show.

We define RoRAC an EVA on segment level using the allocated capital to the segment. Assume an insurance company consists of two segments, $S_{1}$ and $S_{2}$ (see Table 1). The underlying probability space is a Laplace space with four realisations. Therefore each realisation has a probability of one-fourth. The risk capital is calculated using TVaR to a confidence level of 3/4. Figure 2 shows the effects of two strategies differing only for Segment 1 on $R o R A C$ and $E V A$. The party responsible for

\footnotetext{
${ }^{14}$ See Landsman and Valdez (2002), Venter (2004) and Koryciorz (2004).

15 See for example Panjer (2002) using value-at-risk as risk measure.

${ }^{16}$ Using semi-covariance principle instead of covariance principle, the effect is much smaller, see Bamberg et al. (2005).

${ }^{17}$ For a critical discussion of capital allocation see Gründl and Schmeiser (2005).
} 


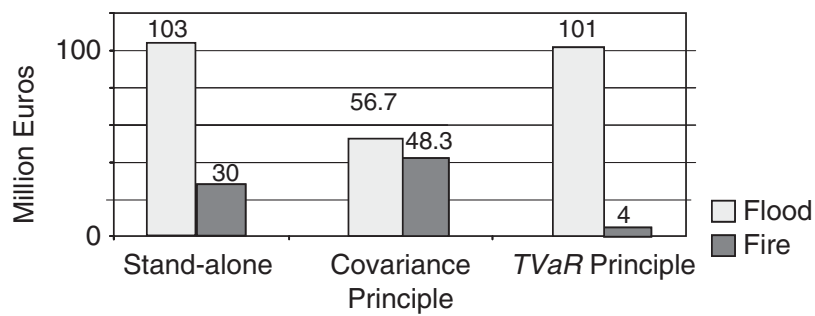

Figure 3. Risk capital stand-alone and using allocation methods.

Table 1 Effects of strategies

\begin{tabular}{lccccccc}
\hline & \multicolumn{3}{c}{ Strategy 1} & & \multicolumn{2}{c}{ Strategy 2 } \\
\cline { 2 - 4 } \cline { 6 - 7 } & $S_{1}$ & $S_{2}$ & Company & & $S_{1}$ & $S_{2}$ & Company \\
\hline Realisation 1 & 42 & 32 & 74 & & 42 & 32 & 74 \\
Realisation 2 & -20 & -4 & -24 & & 0 & -4 & -4 \\
Realisation 3 & 1 & 0 & 1 & & 2 & 0 & 2 \\
Realisation 4 & 4 & -16 & -12 & & -16 & -16 & -32 \\
Expected result & 6.8 & 3.0 & 9.8 & & 7.0 & 3.0 & 10.0 \\
TvaR-allocation & 20 & 4 & 24 & & 16 & 16 & 32 \\
RoRAC (\%) & 34 & 75 & 41 & & 44 & 19 & 31 \\
EVA & 3.8 & 2.4 & 6.2 & & 4.6 & 0.6 & 5.2 \\
\hline
\end{tabular}

Segment 1 will decide on Strategy 2 due to the increase in RoRAC and $E V A$. However, Strategy 1 would be more favourable at company level.

Now we want to show under which conditions the TVaR principle can be used successfully for risk-adjusted performance management in the following sense: Increasing the segment-level $E V A$ leads to an increase of $E V A$ for the company, so that this allocation method gives the "right" incentives for the segment.

In Table $1, S_{1}$ can influence the state in which the worst corporate result is realised as relevant to calculating $T V A R$. However, in practice we often have the situation that set of realisations of the worst company results (set $T$ in the following Remark 1) is independent of strategy selection for other segments. If this is the case the following holds (see also Schlütter): ${ }^{18}$

Remark 1: A company with $n$ segments refers to the TVaR at a confidence level of $1-\alpha$ for risk quantification and uses the $T V a R$ capital allocation principle. Segment $i$ may select strategy $k$ with return $R_{i}^{k}: A \rightarrow \mid \mathrm{R}, k \in\{1, \ldots, m\}$ (where $L_{i}^{k}=-R_{i}^{k}$ ), where the following applies to all $k$ :

$$
\begin{gathered}
T \equiv\left\{a \in A: L_{1}+\ldots+L_{i}^{k}+\ldots+L_{n} \geqslant\right. \\
\left.\operatorname{VaR}_{\alpha}\left(L_{1}+\ldots+L_{i}^{k}+\ldots+L_{n}\right)\right\},
\end{gathered}
$$

\footnotetext{
${ }^{18}$ Schlütter (2006).
} 
that is, $T$ is independent of $k$. Given the $k^{\max } \in\{1, \ldots, m\}$ strategy, where

$$
E V A\left(R_{i}^{k^{\max }}\right)=\max _{k \in\{1, \ldots, m\}} E V A\left(R_{i}^{k}\right)
$$

the following applies:

$$
E V A\left(R_{1}+\ldots+R_{i}^{k^{\max }}+\ldots+R_{n}\right)=\max _{k \in\{1, \ldots, m\}} E V A\left(R_{1}+\ldots+R_{i}^{k}+\ldots+R_{n}\right) .
$$

The remark is simple to confirm by calculation. Therefore if the conditions hold and we use the TVaR allocation principle, that strategy (from a set of given strategies) leading to the highest $E V A$ of a segment $i$ also leads to the highest EVA of the company.

Therefore for practitioners Remark 1 can be very important in the context of ERM, because a capital allocation method is needed not only to set risk limitations for different segments, but also to quantify the effect of management strategies on riskadjusted performance indicators, defined per segment. In this context the question arises if one can find a capital allocation method giving the "right" strategic incentives for the segment. Remark 1 gives an answer to that question, if the condition holds that the insurance company's risk capital is dominated by extreme risk positions. One example for this is where extreme events creating very high losses dominate risk capital, as our simulation study based on real data in the next section shows. Depending on the portfolio structure, the underwriting policy and the reinsurance structure of the company, such extreme losses could be created by natural catastrophes such as storm, earthquake or flood.

Another important point in the context of strategic ERM is the question if the inclusion of a new segment in the portfolio of the company will have positive effects on performance indicators $R o R A C$ and $E V A$ at the company level. We can answer this question viewing the performance of the new segment with the result $R_{\text {new }}=-L_{\text {new }}$ with regard to risk capital of the new segment, if it is defined using incremental capital allocation $R C_{\text {new }}^{\text {inc }}=\rho\left(L+L_{\text {new }}\right)-\rho(L) .{ }^{19}$ The following Remark 2 can be shown by equivalence transformation (see also Schlütter). ${ }^{18}$

\section{Remark 2:}

(a) Assume that $R C_{\text {new }}^{\text {inc }}>0$. Including an additional segment c.p. increases company level $R o R A C$ where $R o R A C$ on the incremental risk capital increases above total $\operatorname{RoR} A C$, that is:

$$
\frac{E\left(R_{\text {new }}\right)}{R C_{\text {new }}^{\text {inc }}}>\frac{E(R)}{\rho(L)} .
$$

(b) Including a new additional segment c.p. will increase company level $E V A$ where segment level $E V A$ (in relation to the incremental risk capital) is positive:

$$
\begin{aligned}
& E\left(R_{\text {new }}\right)-R C_{\text {new }}^{\text {inc }} \cdot r_{\text {cap }}>0 \\
& \quad \Leftrightarrow E\left(R+R_{\text {new }}\right)-\rho\left(R+R_{\text {new }}\right) \cdot r_{\text {cap }}>E V A(R) .
\end{aligned}
$$

\footnotetext{
${ }^{19}$ See Saita (1999) and Cummins (2000).
} 
116

From Eq. (15) we can see that the new segment should be included in the portfolio of the company, if the expected result of the new segment exceeds the additional capital costs.

The following Remark 3 results from Remark 2(b) and the $\rho(R)-\rho\left(R-R_{i}\right) \leqslant \rho_{A}\left(R_{i}\right)$ inequality, which applies to any coherent allocation method $A$ for all segments $i$, meaning that the incremental segment capital represents the lower limit of the allocation contributions in coherent allocation methods (see also Schlütter) ${ }^{18}$.

Remark 3: A company consists of $n$ segments. If a segment $i \leqslant n$ has a positive segment $E V A$ as determined by a coherent allocation method $A$, then hiving off segment $i$ will result in reduction of the total $E V A$ :

$$
\begin{aligned}
& E V A\left(R_{i}\right)=E\left(R_{i}\right)-\rho_{A}\left(R_{i}\right) \cdot r_{c a p}>0 \\
& \Rightarrow E V A(R)>E V A\left(R-R_{i}\right) .
\end{aligned}
$$

Remark 3 can be of high relevance in practice. If companies use a coherent allocation method, for example $T V a R$ allocation method with $T V a R$ as underlying risk measure. Then the allocation method gives the "right" strategic incentives in this context. Therefore if management thinks about strategies to reduce risk capital, hiving off a segment with positive segment $E V A$ will lead to a reduction of total $E V A$. In this case other strategies (e.g. extending reinsurance cover) should be analysed. For practitioners it is important to mention that "segment $i$ " does not always mean a line of business. It can also be a part of a line of business (e.g. special building types).

A similar statement to Remark 2(a) is particularly relevant to reinsurance, where a new segment with result $R_{\text {new }}$ may be evaluated, for example, as a reinsurance result (result as viewed by a ceding company). In this case, $R+R_{\text {new }}$ corresponds to the random variable of net result, which requires evaluating whether the effect of the reinsurance leads to an increase of the performance of the company. Since the riskcapital requirement should decrease after reinsurance, $R C_{n e w}^{i n c}<0$ will usually apply. Similarly, we assume $E\left(R_{\text {new }}\right)<0$, as the reinsurance premium expectation will exceed the expectation value of recoveries of the reinsurance company.

Therefore in the context of reinsurance the following applies (see Schradin): ${ }^{20}$

$$
\frac{\rho(\text { GrossLoss })-\rho(\text { NetLoss })}{\rho(\text { NetLoss })}>\frac{E(\text { GrossResult })-E(\text { NetResult })}{E(\text { NetResult })},
$$

where GrossLoss $=-$ GrossResult. This means that a reinsurance contract will increase company $R o R A C$ where the relative reduction in risk-capital requirement exceeds the relative reduction in the corporate result's expectation value.

Assume that $R_{i}, 1 \leqslant i \leqslant m$, represent the reinsurance results for the reinsurance contract $i$. Using a complete allocation method where the net risk-capital requirement is fully allocated to the gross result and reinsurance contracts, the following applies:

$$
\begin{gathered}
E V A(\text { NetResult })=E V A(\text { Gross Result }) \\
+E V A\left(R_{1}\right)+\ldots+E V A\left(R_{m}\right)
\end{gathered}
$$

\footnotetext{
${ }^{20}$ Schradin (1994).
} 
If the allocation method used is also coherent, Remark 3 implies that the company will increase its $E V A$ due to the reinsurance contract $k$ with positive $E V A\left(R_{k}\right)$. Note that $E V A\left(R_{k}\right)$ considers the diversification in the portfolio of the ceding company by using the allocated capital.

Therefore the capital allocation methods together with risk-adjusted performance indicators, $E V A$ and $R o R A C$, may indeed be used for a successful strategic riskadjusted performance management giving the "right" incentives on segment level, if the presented requirements on allocation methods are fulfilled. However, strategic corporate management should not be based solely on $R o R A C$ and $E V A$, as the selection of the underlying risk measure and security level alone have an essential impact on the choice of the efficient strategy.

\section{Simulation study: Management strategies in the context of multi-year ERM}

In the following simulation study we want to give an example how a multi-year internal model can be used in strategic ERM.

The internal simulation model presented here is based on a five-year period using 100,000 simulations. We illustrate the applicability of the model using real-world data and an internal model actually in use at a medium-sized German non-life insurance company. To protect the anonymity of the company, we transformed all data so as to change the absolute values but not the underlying risk structure. In our application, we rely on the internal model presented in Diers ${ }^{6}$ and extend this model as described in the section "Model approach for measuring multi-year risk capital" above. ${ }^{21}$

Two types of assets (high- and low-risk investments) and three types of claims (catastrophe, large and attritional (base) claims) are integrated into the model, which can be simulated according to adequate probability distributions, subject to a given dependency structure. We consider four insurance segments: storm, flood, hail, which are dominated by natural catastrophes, and "All other Lines of Business", as well as the investment segment.

We define multi-year risk capital using simulated multi-year insurance and investment results via multi-year development of economic capital as described in the section "Model approach for measuring multi-year risk capital".

For modelling natural catastrophes such as storms see Diers. ${ }^{22}$ The time at which extreme events take place has been simulated in order to address the potential need for short-term liquidity in capital investment strategy. In the asset model for each scenario management rules (sales priorities) define which assets have to be sold depending on the level of liquidity required.

In the case of scenarios with adverse developments on the capital markets or natural catastrophes, the liquidity requirement may not be fulfilled. One of management's major responsibilities is to ensure that these scenarios are minimised by adequate underwriting policy, sufficient reinsurance protection and appropriate asset allocation. In the following we want to give an incentive to use internal models to analyse the

\footnotetext{
${ }^{21}$ For the study we used the EMB simulation software.

${ }^{22}$ Diers (2009).
} 
118

different strategic instruments in the context of an ORSA process by quantifying the effects on the risk-adjusted key performance indicators of the example company.

Our example company mainly underwrites insurance policies with private and low industrial businesses. We have assumed a consistent underwriting policy and asset allocation within the five-year period. In addition we assumed that the claims that will occur in the following five years simulated will be stochastically independent of one another (concerning the different years).

At time $t=0$, the example company has economic capital $E c C a p_{0}$ amounting to $€ 135$ million. In an ORSA process, management decides to take $T V a R$ at a confidence level of 99.8 per cent as a risk measure for one year risk-capital requirement, and $T V a R$ at a lower confidence level of 99.5 per cent in the five-year risk-capital requirement. We have set capital costs $r_{\text {cap }}=15$ per cent and only refer to this for risk capital, resulting in a risk-adjusted $E V A_{-} r a$. Additional risk-free interest on economic resources has already been deducted from the investment result for benchmarking purposes. Therefore the investment result has been reduced by risk-free interest (on economic capital and liabilities). Risk-free interest represents a benchmark for investors, risk-free interest on economic capital has been given in a separate position not considered here.

We have used the TVaR allocation principle to identify risk factors (see the section "Capital allocation for performance management in ERM"). Table 2 shows risk and return indicators in the insurance segments shown as gross, that is, before reinsurance. We have assumed a stochastic independence between results from the different insurance segments (lines of business) and between insurance and investment results with the exception of hail and storm, where we have assumed a slight tail dependency.

Before reinsurance, the storm segments constitute the dominating risk factor affecting the company. According to TVaR allocation, storm segments need a oneyear risk capital of $€ 296$ million where all other segments together need a negative risk capital of $-€ 5$ million. This shows that the other segments do not contribute to the risk capital of the company, because storm is the dominating risk. Only hail shows a positive allocated risk capital because of the slight tail dependency concerning storm and hail results.

Table 2 Risk and return indicators using actual Strategy

\begin{tabular}{|c|c|c|c|c|}
\hline \multirow[t]{2}{*}{ Million euros } & \multicolumn{4}{|c|}{ Actual strategy } \\
\hline & Return mean & Risk capital stand-alone & Allocation TvaR-principle & $E V A$ \\
\hline Storm & 11.3 & 300 & 296 & -33.2 \\
\hline Flood & 2.1 & 50 & -1 & 2.3 \\
\hline Hail & 2.8 & 40 & 4 & 2.3 \\
\hline All other LoB & 2.5 & 44 & 0 & 2.5 \\
\hline Investment & 5.3 & 45 & -8 & 6.4 \\
\hline Company & 24.0 & 478 & 291 & -19.6 \\
\hline Diversification & \multirow{3}{*}{\multicolumn{2}{|c|}{$\rho\left(\operatorname{CumLoss}(1)>\operatorname{EcCap}_{0}\right)$}} & $187(39 \%)$ & \\
\hline Shortfall (one year) & & & $1.9 \%$ & \\
\hline Risk capital (five years) & & & 370 & \\
\hline Shortfall (five years) & \multicolumn{2}{|c|}{$\rho(\operatorname{CumLoss}(5)>\operatorname{EcCap})$} & $9.0 \%$ & \\
\hline
\end{tabular}




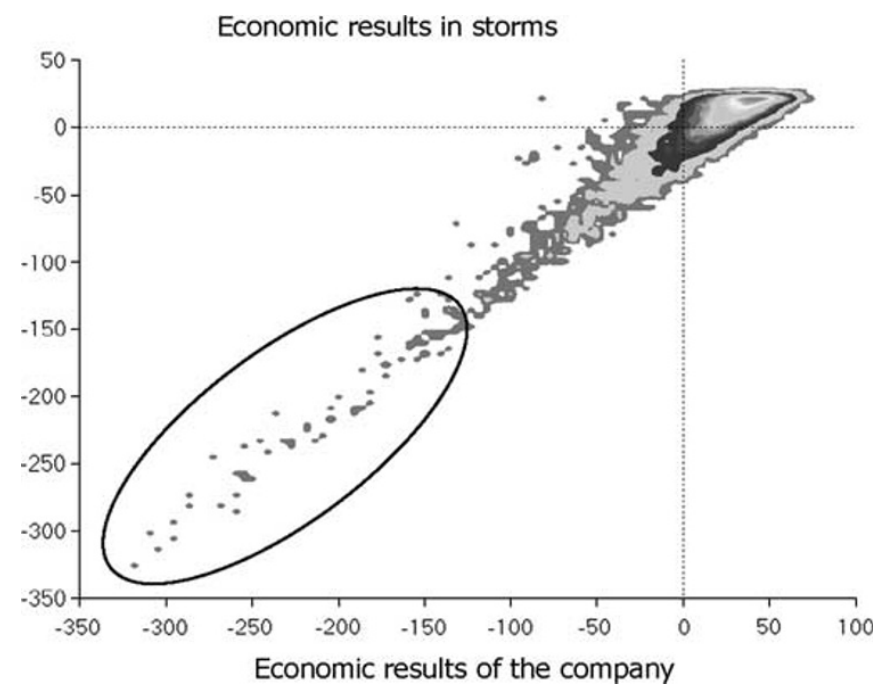

Figure 4. Dependency structure in storms and company-level results using actual strategy (10,000 simulations).

We use Figure 4 to clarify this effect. It shows the dependency structure in storms and company-level results using 10,000 simulations. Note that the storm results are part of the company-level results. One can see that the worst company results occur together with the worst storm results, so storm risk dominates company risk. The diversification effect between the four lines of business (storm, flood, hail and others) and investment results is relatively low at 39 per cent due to the dominance of storm risk. The shortfall probability is very high at 1.9 per cent for one year, and extremely high over five years (9.0 per cent), as the $€ 135$ million in economic capital will not be enough to cover the company's risk-capital requirement for one year and for five years (€370 million). According to Solvency II the one-year shortfall probability has to be less than 0.5 per cent. Therefore the actual strategy does not only fail internal management requirements defined in an ORSA process, but also regulatory requirements following Solvency II.

Our aim is to test how risk-lowering strategies will affect the risk-return situation in our example company. Table 3 gives a survey of the strategies applied.

In Strategy 1, all other lines of business that are not influenced by natural catastrophes such as storm, hail and flood should be extended by 20 per cent (increase in the number of contracts) in order to generate increased returns and to benefit from increased diversification effects. ${ }^{23}$ To reduce risk capital requirements a $€ 250$ deductible is applied to policy-holders in storm insurance segments, where the reduction in claims and regulation costs due to the deductibles are completely passed

${ }^{23}$ The reason why lines of business dominated by storm, hail and flood are not included in the growth rate is that management has decided to limit future risk-taking in those lines of business as this represents the major source of underwriting risk in this company. 
Table 3 Survey of strategies

Strategy $1 \quad$ Growth of 20 per cent in all lines of business except storm, hail, flood; Introduction of $€ 250$ deductibles in storm

Strategy $2 \quad$ Strategy 1 plus reinsurance in storm segments (event-excess-of-loss contract)

Strategy $3 \quad$ Strategy 2 plus raise the part of high-risk investments from 5 to 10 per cent

Table 4 Risk and return indicators using Strategy 1

\begin{tabular}{|c|c|c|c|c|}
\hline \multirow[t]{2}{*}{ Million euros } & \multicolumn{4}{|c|}{ Strategy 1} \\
\hline & Return mean & Risk capital stand-alone & Allocation TvaR-principle & $E V A$ \\
\hline Storm & 8.5 & 225 & 219 & -24.3 \\
\hline Flood & 2.1 & 50 & -1 & 2.3 \\
\hline Hail & 2.8 & 40 & 4 & 2.3 \\
\hline All other LoB & 2.9 & 49 & 0 & 2.9 \\
\hline Investment & 5.3 & 45 & -8 & 6.4 \\
\hline Company (one year) & 21.7 & 409 & 214 & -10.4 \\
\hline Diversification & & & $195(48 \%)$ & \\
\hline Shortfall (one year) & \multicolumn{2}{|c|}{$\rho\left(\operatorname{Max} \operatorname{Loss}(1)>\operatorname{EcCap}_{0}\right)$} & $0.9 \%$ & \\
\hline Risk capital (five years) & & & 276 & \\
\hline Shortfall (five years) & \multicolumn{2}{|c|}{$\rho\left(\operatorname{Max} \operatorname{Loss}(5)>E c \operatorname{Cap}_{0}\right)$} & $6.5 \%$ & \\
\hline
\end{tabular}

on to the client by premium adjustments (an alternative might be here to assume that only a portion of the reduction is passed on to the policy-holder, which would ceteris paribus enhance the risk and return situation of the insurer). This leads to an unchanged (stand-alone) $\operatorname{RoR} A C=11.3 / 300=8.5 / 225=0,038$ in storm insurance (see Table 4 where return decreases from $€ 11.3$ million to $€ 8.5$ million and risk capital decreases from $€ 300$ million to $€ 225$ million).

In storm insurance, even low deductibles of $€ 250$ lead to a loss reduction of about 25 per cent. This significant loss reduction is a result of the enormous number of small claims that occur due to storm events. Therefore deductibles in storms have a remarkable effect on risk capital. Introducing deductibles tends to be unpopular with policy-holders, resulting in probable cancellations and cross-cancellations. We have not considered these effects in our calculations, but they should not be neglected in practice. For modelling deductibles we rely on Diers. ${ }^{22}$

Despite expansion in the non-catastrophe segments (all other LoB), risk-capital requirement hardly increases in the stand-alone view from $€ 44$ million to $€ 49$ million, because of the high diversification effects within and between these lines of business.

The somewhat lower risk situation in storm results in increased diversification effects to 48 per cent. Since the risk capital in our example company is dominated by storm risk, the conditions in Remark 1 (see the section "Capital allocation for performance management in ERM") are fulfilled for all strategies unaffected by this dominance, which even applies to Strategy 1. Remark 1 therefore implies that strategies which increase the segment-level $E V A$ also increase the $E V A$ for the company.

In our example, increasing the segment $E V A$ for storm and all other lines of business leads to an increase in $E V A$ for the company, but this is still strongly negative 
at $-€ 10.4$ million. The one-year risk-capital requirement of $€ 214$ million is still substantially higher than the company's economic capital of $€ 135$ million, and the oneyear shortfall probability is therefore still high, so that the Solvency II requirements are not fulfilled. The same holds for the five-year risk capital of $€ 276$ million and the five-year shortfall probability.

Strategy 2 is based on Strategy 1. In addition to Strategy 1, the storm segments are reinsured by an event-excess-of-loss contract. For modelling reinsurance contracts we rely on Eling and Toplek. ${ }^{7}$ We have calculated the reinsurance premiums using technical pricing methods (see Diers) ${ }^{6}$.

Reinsurance in the storm segments substantially lowers one-year risk-capital requirement in the storm segments to $€ 80$ million. The allocated risk-capital requirement reveals that now the other segments also contribute to the company's risk-capital requirement. However, storm risk still dominates the risk-capital requirement at company level (Table 5).

Figure 5 shows 10,000 simulation results of economical results in storm vs. economical results of the company. We see that by following Strategy 2 many of the worst scenarios of the company still fall together with the worst scenarios in storm insurance, which shows the further domination of storm risks in these scenarios (see black marking). Comparison of Figures 4 and 5 reveals a changed dependency structure, showing that the domination of storm risks following Strategy 2 is much less in comparison to the actual strategy.

The substantial reduction in risk-capital requirement in storm segments leads to a substantial increase in diversification effects to 66 per cent. Now the one-year riskcapital requirement of the company, $€ 90$ million, can be covered by the company's economic capital of $€ 135$. This leads to a one-year shortfall probability fulfilling the regulatory requirements (Solvency II). Apart from that, company $E V A$ turns positive at $€ 2.2$ million.

The effect of reinsurance agreements can be assessed in Remark 3 together with Eq. (18) in the section "Capital allocation for performance management in ERM". Using the definitions of the section the Strategy 1 describes the situation before reinsurance ("gross") and Strategy 2 after reinsurance ("net"). The reinsurance

Table 5 Risk and return indicators using Strategy 2

\begin{tabular}{lcccr}
\hline Million euros & \multicolumn{3}{c}{ Strategy } \\
\cline { 2 - 5 } & Return mean & Risk capital stand-alone & Allocation TvaR-principle & EVA \\
\hline Storm & 2.5 & 80 & 53 & -5.5 \\
Flood & 2.1 & 50 & 15 & -0.1 \\
Hail & 2.8 & 40 & 9 & 1.5 \\
All other LoB & 2.9 & 49 & 7 & 1.9 \\
Investment & 5.3 & 45 & 6 & 4.4 \\
Company & 15.7 & 265 & 90 & 2.2 \\
Diversification & & $175(66 \%)$ & \\
Shortfall (one year) & $\rho\left(\operatorname{Max} \operatorname{Loss}(1)>\right.$ EcCap $\left._{0}\right)$ & $0.02 \%$ & 125 \\
Risk capital (five years) & & $0.4 \%$ & \\
Shortfall (five years) & $\rho\left(\operatorname{Max} \operatorname{Loss}(5)>\right.$ EcCap $\left._{0}\right)$ & & \\
\hline
\end{tabular}




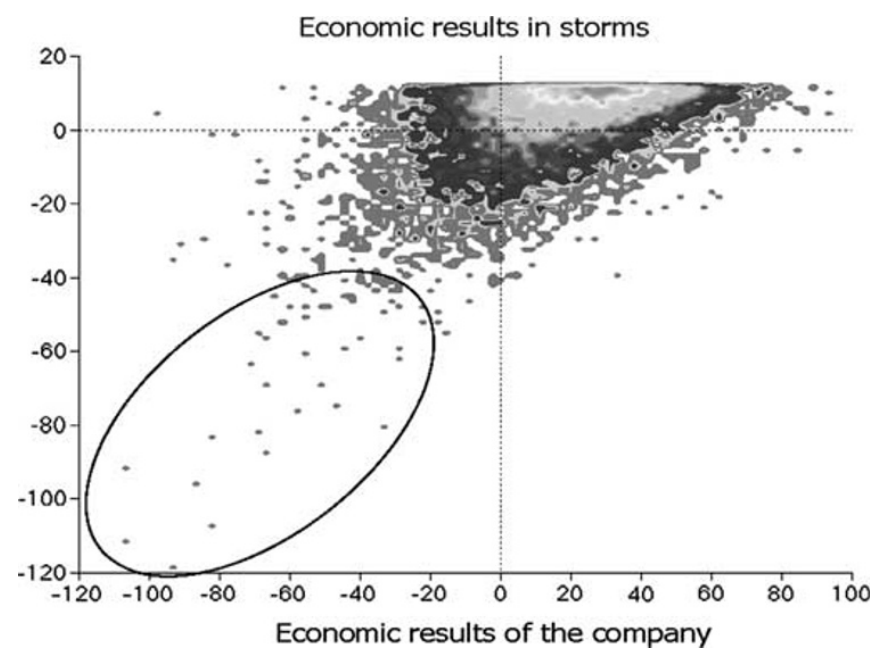

Figure 5. Dependency structure in storms and company-level results using Strategy 2 (10,000 simulations).

contract has a positive $E V A(R)$ and so leads to an increase of $E V A$ on company level:

$$
\begin{gathered}
E V A(\text { Net Result })=2.2, \text { EVA(GrossResult }) \\
\quad=-10.4 \text { and } E V A(R)=12.6 .
\end{gathered}
$$

However, the company still has to cover its five-year risk-capital requirement from its own economic capital at $t=0$, enabling the company to remain over five years without external capital supply. We see that the $€ 125$ million in risk-capital requirement for the next five years are covered by the economic capital of the company, €135 million, too.

In order to increase the average return and in order to benefit from further diversification potential we define a Strategy 3 changing the asset allocation in the way that the part of high-risk investments is raised from actual 5 per cent to 10 per cent. Background for this strategy is the fact that the five-year risk-capital of $€ 125$ million requirement lies below the economic capital of the company, $€ 135$ million, so that we have a further $€ 10$ million for our multi-year risk position. This should be used in order to increase $E V A$ on the company level.

Strategy 3 leads to an increase in one-year risk capital for investment results from $€ 45$ million to $€ 61$ million (Table 6). This leads to a low increase in one-year risk capital on the company level from $€ 90$ million to $€ 92$ million resulting from a further increase in diversification. The company can still cover its five-year risk-capital requirement from its own economic capital at $t=0$, because the $€ 132$ million in riskcapital requirement for the next five years are covered by the economic capital of the company (€135 million).

The simulation study shows that the TVaR allocation principle using TVAR as risk measure can be used for identifying risk dominating positions in the portfolio, because it allocates the amount of risk capital to each segment as it contributes to the whole 
Table 6 Risk and return indicators using Strategy 3

\begin{tabular}{|c|c|c|c|c|}
\hline \multirow[t]{2}{*}{ Million euros } & \multicolumn{4}{|c|}{ Strategy 3} \\
\hline & Return mean & Risk capital stand-alone & Allocation TvaR-principle & $E V A$ \\
\hline Storm & 2.5 & 80 & 48 & -4.7 \\
\hline Flood & 2.1 & 50 & 11 & 0.4 \\
\hline Hail & 2.8 & 40 & 10 & 1.3 \\
\hline All other LoB & 2.9 & 49 & 5 & 2.2 . \\
\hline Investment & 7.4 & 61 & 17 & 4.8 \\
\hline Company (one year) & 17.7 & 280 & 92 & 4.0 \\
\hline Diversification & \multirow{3}{*}{\multicolumn{2}{|c|}{$\rho\left(\operatorname{Max} \operatorname{Loss}(1)>\operatorname{EcCap}_{0}\right)$}} & $189(67 \%)$ & \\
\hline Shortfall (one year) & & & $0.05 \%$ & \\
\hline Risk capital (five years) & & & 132 & \\
\hline Shortfall (five years) & \multicolumn{2}{|c|}{$\rho\left(\operatorname{Max} \operatorname{Loss}(5)>\operatorname{EcCap}_{0}\right)$} & $0.5 \%$ & \\
\hline
\end{tabular}

risk capital. In this context it should be used in practice. Moreover the TVaR allocation principle can serve as an important base for strategic management decisions in the following sense (if the assumptions in Remark 1, section "Capital allocation for performance management in ERM", hold): Increasing the segment-level EVA leads to an increase of $E V A$ for the company. This means that defining risk-adjusted performance indicators on segment level using $T V a R$ allocation principle can give the "right" incentives in strategic ERM.

On the other hand we can conclude from the simulation study and from the section "Capital allocation for performance management in ERM" that generally we neither have the "right" risk measure nor the "right" allocation method for all portfolio structures and problems. This also holds for coherent risk measures and allocation methods. Table 2 can serve as an example that shows the capital allocation (TVaR principle) following the actual strategy, allocating more than the total risk capital to the storm segment and so leading to a negative allocated risk capital for the other segments. This allocation method quantifies the risk dominance of storm risks in an adequate way and can be used for management decisions as described above, but negative allocated risk capital can cause a problem in practice in the context of risk limitation on segment level.

\section{Conclusion}

ERM strategies should be evaluated and managed from a multi-year perspective. In the actual literature several questions concerning the use of internal models in a multiyear management context are not answered to date. In this paper we presented a multiyear model approach. A multi-year risk-capital concept was applied to enable the company's ORSA as a part of ERM on a multi-year basis. Moreover, regulators accept the use of internal risk models for calculating risk capital requirements under Solvency II and the Swiss Solvency Test if such internal models are actually used by the company. In our simulation study we showed how such an internal model could be integrated into an insurer's strategic management processes. 
124

In the context of strategic ERM a capital allocation method is needed (1) for setting risk limitations for different segments, such as lines of business and investments, and (2) in order to quantify the effect of management strategies on risk-adjusted performance indicators such as $E V A$ or risk adjusted capital $(R o R A C)$ for those segments. The adequacy of the allocation method depends on the portfolio structure and on the aim that should be followed with the capital allocation. Generally there is no known allocation method giving "right" incentives for each portfolio structure and each managerial problem. We showed examples of allocation methods giving the "wrong" incentives in order to point out the importance of choosing adequate allocation methods in each particular managerial context. We defined assumptions so that the TVaR capital allocation method may successfully be used for strategic risk-adjusted performance management, which means increasing the segment-level $E V A$ leads to an increase of $E V A$ for the company, so that this allocation method gives the "right" incentives for the segment.

In value and risk-based management, strategies should be selected in such a way as to fulfil the requirements on risk-capital coverage with economic capital (e.g. risk limitation) while achieving the highest possible return by adequate underwriting policy, sufficient reinsurance cover and suitable asset allocation strategy. Moreover risk and return profile of the company should be set taking future underwriting years into account. This has led us to quantify the effect of strategies applied to a five-year period on risk and return positions. We used a multi-year simulation model based on empirical data in order to give a realistic idea of defining suitable management strategies on segment level in order to improve the risk and return situation of the company. Moreover the simulation study should give an idea of the ORSA process.

It should be noted that we take a pure solvency perspective here and that the riskbased capital is a lower bound, not necessarily the optimal capital level. The optimum equity level with optimum company division strategy should be determined by shareholder value (see Gründl and Schmeiser ${ }^{11}$ ). In our study we referred to improvement in risk-return trade-off rather than optimisation in the whole company, where we chose out of a variety of potential strategies the best strategy with the most positive effect on the risk-adjusted key performance indicators $R o R A C$ and $E V A$.

The strategies shown here should serve as examples, encouraging the use of multiyear internal models in strategic ERM as a basis for decision-making. In addition the simulation study should give an idea of the ORSA process, which will be required in the new regulatory framework of Solvency II.

\section{Acknowledgement}

I am grateful to the feedback of the judges and Martin Eling, Peter England and Hans-Joachim Zwiesler for their valuable comments and suggestions.

\section{References}

Artzner, P., Delbaen, F., Eber, J-M. and Heath, D. (1999) 'Coherent measures of risk', Mathematical Finance 9(3): 203-228.

CEIOPS (2008) Own Risk and Solvency Assessment (ORSA), Issues Paper, http://www.gcactuaries.org/ documents/ceiops_issues_paper_orsa.pdf. 
Cummins, J.D. (2000) 'Allocation of capital in the insurance industry', Risk Management and Insurance Review 3(1): 7-27.

Denault, M. (2001) 'Coherent allocation of risk capital', The Journal of Risk 4(1): 1-34.

Diers, D. (2007) 'Interne Unternehmensmodelle in der Schaden- und Unfallversicherung —Entwicklung eines stochastischen internen Modells für die wert- und risikoorientierte Unternehmenssteuerung und für die Anwendung im Rahmen von Solvency II', ifa-Verlag, http://www.ifa-ulm.de.

Diers, D. (2008a) 'Aspekte der rendite- und risikoorientierten Steuerung in der Schaden- und Unfallversicherung', Schriftenreihe SCOR Deutschland, Nr. 7, Verlag Versicherungswirtschaft, Karlsruhe.

Diers, D. (2008b) 'Der Einsatz mehrjähriger Interner Modelle zur Unterstützung von Managemententscheidungen', Supplement: ZVersWiss, 97(1): 91-112.

Diers, D. (2009) 'Stochastic modelling of catastrophe risks in DFA models', ASTIN Colloquium in Manchester, July 2008, published in German Risk and Insurance Review, Vol. 5, 2009, pp. 53-79, http:// www.risk-insurance.de/aufsaetze/200901/Diers.pdf.

Diers, D. (2010) A multi-year risk capital concept for enterprise risk management, Working Paper University of Ulm (2010), presented at the International Congress of Actuaries (Cape Town, March 2010).

Elderfield, M. (2009) 'Solvency II: Setting the pace for regulatory change', The Geneva Papers on Risk and Insurance-Issues and Practice 34(1): 35-41.

Eling, M. and Toplek, D. (2009a) 'Modeling and management of nonlinear dependencies-Copulas in dynamic financial analysis', Journal of Risk and Insurance 76(3): 651-681.

Eling, M. and Toplek, D. (2009b) 'Risk and return of reinsurance contracts under copula models', European Journal of Finance 15(7): 751-775.

Gründl, H. and Schmeiser, H. (2002) 'Marktwertorientierte Unternehmens- und Geschäftsbereichssteuerung in Finanzdienstleistungsunternehmen', Zeitschrift für die Betriebswirtschaft 8(72): 797-822.

Gründl, H. and Schmeiser, H. (2007) 'Capital allocation for insurance companies - What good is it?' The Journal of Risk and Insurance 74(2): 301-317.

Kaufmann, R., Gadmer, A. and Klett, R. (2003) 'Introduction to dynamic financial analysis', $A S T I N$ Bulletin 31(1): 213-249.

Koryciorz, S. (2004) 'Sicherheitskapitalbestimmung und -allokation in der Schadenversicherung: Eine risikotheoretische Analyse auf der Basis des Value-at-Risk und des Conditional Value-at-Risk', Veröffentlichungen des Instituts für Versicherungswissenschaft der Universität Mannheim, Vol. 67, VVW, Karlsruhe.

Landsman, Z. and Valdez, E.A. (2003) 'Tail conditional expectations for elliptical distributions', North American Actuarial Journal 7(4): 55-71.

Liebenberg, A.P. and Hoyt, R.E. (2003) 'The determinants of enterprise risk management: Evidence from the appointment of Chief Risk Officers', Risk Management and Insurance Review 6(1): 37-52.

Panjer, H. (2002) Measurement of Risk, Solvency Requirements and Allocation of Capital within Financial Conglomerates, Research Report 01-15, Institute of Insurance and Pension Research, University of Waterloo.

Saita, F. (1999) 'Allocation of risk capital in financial institutions', Financial Management 28(3): 95-111.

Schlütter, S. (2006) Die Berücksichtigung von Diversifikationseffekten im Controlling von Schadenversicherungen, Diplomarbeit: Universität Ulm.

Schradin, H.R. (1994) 'Erfolgsorientiertes Versicherungsmanagement: Betriebswirtschaftliche Steuerungs konzepte auf risiko theoretischer Grandlage', Karlsruhe, Germany: Verlag Versicherungswirtschaft $\mathrm{GmbH}$, Band 43.

Venter, G. (2004) 'Capital allocation survey with commentary', North American Actuarial Journal 8(2): 96-107.

\section{About the Author}

Dorothea Diers, PhD, is Head of risk controlling at Provonzial NordWest Holding, Muenster, and Lecturer in Actuarial Sciences and Enterprise Risk Management at Ulm University, Germany. 